\title{
Impact of Adopting Agricultural Extension Recommendations on the Success of Palm Cultivation
}

\author{
Mohammad Altarawneh ${ }^{1} \&$ Ebraheem Altahat ${ }^{1}$ \\ ${ }^{1}$ Department of Agricultural Economics and Extension, Faculty of Agriculture, Jerash University, Jerash 26150, \\ Jordan \\ Correspondence: Mohammad Altarawneh, Department of Agricultural Economics and Extension, Faculty of \\ Agriculture, Jerash University, Jerash 26150, Jordan. E-mail: ms_tarawneh@yahoo.com
}

Received: July 15, 2013 Accepted: August 15, 2013 Online Published: September 15, 2013

doi:10.5539/jas.v5n10p135 URL: http://dx.doi.org/10.5539/jas.v5n10p135

\begin{abstract}
This study aimed at analyzing the impact of the adoption of agricultural extension recommendations on the success of palm cultivation in Jordan. Data were collected via structured questionnaire from 40 palm farmers in DairAlla area in Jordan. A comprehensive survey through a well-constructed questionnaire with items related to the objectives of the study was used to collect necessary data. Descriptive statistical analysis procedure was followed. Means, standard deviations, and percentages were determined; $\mathrm{T}$ and $\mathrm{f}$ tests, correlations, and regression analysis were conducted. The results of the study showed that there was a medium level in the degree of adoption of the investigated farmers of the agricultural extension recommendations. Recommendations related to land preparation for agriculture, disease control, and irrigation methods were the most adopted recommendations. The results also revealed that there was a significant effect on the farmers' adoption of recommendations at $5 \%$ level for education level, farming experience, and land area variables.
\end{abstract}

Keywords: adoption, extension recommendations, palm cultivation, Dair Alla

\section{Introduction}

Agricultural extension is one of the most important distinct developmental organs that aim to bring about development in the rural community in general and agriculture in particular (Al-Rimawi et al.,1996); it is designed primarily to provide various extension services to farmers (AL-Saab, 2008). The importance of agricultural extension is obvious in the field of date palm cultivation in most areas of the world, still, some of which uses inherent technology and expertise in the palm cultivation (Hamade, 2006). The past fifteen years has noticed significant expansion in palm cultivation, and this is mainly due to that the palm is of the most adapted plants to arid environment (Alawaideh et al., 2008).Because of what is available in Jordan from good environmental conditions, and due to the appropriate investment opportunities in the field of date palm cultivation as well as its economic importance in the agricultural sector, this crop has received great interest by both the consumer and the state (Ministry of Agriculture, 2013).

Agricultural extension recommendations meant for farmers' adoption are designed to firstly improve farmers' yield (Benjamin, 2013), Many studies have been conducted to look into adoption of improved crop production technologies packaged by Agricultural Extension Department, Like (Opare, 1977; Sher et al., 2001; Agbarevo \& Obinne, 2009; Agbarevo, 2010; Agbarevo, 2011) that studies indicate the importance of the Agricultural extension recommendations palm cultivation.

In Jordan, the area planted with palm trees increased from 1082.9 to 17690.2 dunums during the period from 1994 -2011. This increase was accompanied by increase in the production of dates from 892.5 tons to 11213.40 tons. The consumption patterns prevailing in Jordan and the high prices of good varieties of dates support this increase in production. Such conditions raised number of fruit-bearing trees from 14857 Palm tree to $234048 \mathrm{Palm}$ tree during the period between 1994 - 2011 (Department of Statistics, 2012).

Any attempt to develop the palm cultivation should concentrate on the degree of adopting the ideas and developed agricultural methods recommended by the extension agents by the farmers (Benjamin, 2013; Hadrous, 2009). This study was conducted to examine the degree to which palm dates farmers adopt agricultural extension 
recommendations in DairAlla area in Jordan and to investigate the impact of this adoption on palm cultivation in Jordan.

\section{Objectives of the Study}

The main objective of this study is to analyze the impact of adopting the agricultural extension recommendations on the success of palm cultivation in Jordan. To achieve this objective, the following secondary objectives should be achieved:

1) Measurement of the importance of adoption of palm growers to extension recommendations.

2) Analyze the relationship between the independent characteristics and the degree of adoptions for those recommendations should be analyzed.

\section{Questions of the Study}

This study tries to answer the following questions;

1) Are palm growers adopting extension recommendations?

2) How extension recommendations are important for palm growers?

3) What is the level of adopting extension recommendations by palm growers?

4) Is there any impact of the independent characteristics (variables) on the degree of adoption of extension recommendations?

\section{Methodology and Procedure}

4.1 The Sample

A comprehensive survey method was used to collect the data for this study. Forty palm growers were covered in the study. A constructed questionnaire was used to collect primary data. The sample covered all the palm growers in DairAlla area, one of the most important palm production areas in Jordan. DairAlla area is a major cultivation part of Balqa Governorate. It resembles about $22 \%$ of the total area of the governorate with about $240 \mathrm{~km}^{2}$. The study area is as a long of $30 \mathrm{~km}$ along Jordan River (Ministry of Interior, 2012).The needed secondary data was collected from its main sources such as Ministry of Agriculture, Ministry of Interior, Ministry of Irrigation and Water, and Balqa Agricultural Directorate. Data were collected during 2013 agricultural season.

\subsection{The Questionnaire}

The main tool to collect data was a questionnaire. The questionnaire included the necessary information to achieve the goals of the study. This information includes; characteristics of the farmer (age, education level, and experience), area of the farm, the degree of adopting extension recommendations by the farmer, and the level of adopting extension recommendations by the farmer. The farmer age and experience were in years. The farm area was in Dunums. The education level of the farmer was given six levels as follows; 1 illiterate, 2 can read and write, 3 secondary education, 4 diploma level, 5 first university degree level, 6 post graduated level. The degree of adopting extension recommendations by the farmer was given five degrees; 0 unimportant, 1 slightly important, 2 important with medium degree, 3 important, 4 very important. Farmers were asked questions about the degree they adopt extension recommendations. Three levels were assigned for adopting extension recommendations by the farmer in the study; high, medium, and low adoption level. The scores of the highest adopting level range supposed to range from (2.68) to 4 ) and for the medium level the scores range was 1.34-2.67, and for the low-level zero 1.33 .

\subsection{The Statistical Analysis}

After confirming the normal distribution of the data the Statistical Package of Social Sciences (SPSS) software was used to analyze data. Descriptive statistical analysis procedure was followed in this study to determine Likert Scale associated items. Means, standard deviations, and percentages were determined. $\mathrm{T}$ and $\mathrm{f}$ tests, correlations, and regression analysis were conducted.

\section{Results and Discussion}

The results and discussion will be presented according to the questions of the study.

\subsection{Are Palm Growers Adopting Extension Recommendations?}

The results of the statistical analysis for this question are shown in Table 1. 
Table 1. Percentages of adopting extension recommendations by interviewed farmers

\begin{tabular}{lccc}
\hline \multirow{2}{*}{ Recommendation } & \multicolumn{3}{c}{ Adoption } \\
\cline { 2 - 4 } & No of Farmers & Percentage & Rank \\
\hline Preparation and processing of the cultivation land & 32 & $80 \%$ & 1 \\
Propagation methods & 23 & $57.5 \%$ & 5 \\
Planting methods & 27 & $67.5 \%$ & 3 \\
Irrigation methods & 19 & $47.5 \%$ & 7 \\
Irrigation schedules & 22 & $55 \%$ & 6 \\
Impregnation & 23 & $57.5 \%$ & 5 \\
Fertilization & 25 & $62.5 \%$ & 4 \\
Control methods & 28 & $70 \%$ & 2 \\
Reaping the fruits & 7 & $17.5 \%$ & 8 \\
\hline
\end{tabular}

Source: Survey results.

As shown in Table 1, there was an adoption of the extension recommendations, but there was a large variation in this adoption according to the activity. The overall adoption percentage of the farmers ranges from $17.5 \%$ for recommendations related to reaping the fruits, indicating less importance of recommendations for this activity because farmers are well skilled in this manner and do not need recommendations in this regard, to $80 \%$ for recommendations related to the preparation and processing of the cultivation land indicating high importance of recommendations for this activity because farmers lack experience in this activity at the beginning of their farming activity.

\subsection{How Extension Recommendations are Important for Palm Growers?}

The results of the statistical analysis for this question are shown in Table 2.

Table 2. Distribution of interviewed farmers according to the importance of adoption

\begin{tabular}{lccc}
\hline \multirow{2}{*}{ Recommendation } & \multicolumn{3}{c}{ Importance of Adoption } \\
\cline { 2 - 4 } & Mean & St. Deviation & Rank \\
\hline Preparation and processing of the cultivation land & 1.97 & 1.22 & 1 \\
Propagation methods & 1.52 & 1.21 & 4 \\
Planting methods & 1.30 & 0.85 & 7 \\
Irrigation methods & 1.85 & 1.23 & 2 \\
Irrigation schedules & 1.45 & 1.03 & 6 \\
Impregnation & 1.52 & 0.98 & 5 \\
Fertilization & 1.30 & 0.82 & 8 \\
Control methods & 1.65 & 1.02 & 3 \\
Reaping the fruits & 1.00 & 0.84 & 9 \\
Average & 1.51 & 0.38 & \\
\hline
\end{tabular}

Source; Survey results.

As shown in Table 2, the important of adopting extension recommendations by palm growers in study area was with an average of 1.51 indicating a medium important according to our classification in section 2.2 with a standard deviation of 0.38 . This is due to the weakness of extension services provided to farmers.

\subsection{What is the Level of Adopting Extension Recommendations by Palm Growers?}

The results of the statistical analysis for this question are shown in Table 3. 
Table 3. Distribution of interviewed farmers according to the level of adoption

\begin{tabular}{llllll}
\hline \multirow{2}{*}{ The level } & \multirow{2}{*}{ Class } & \multicolumn{3}{c}{ Adoption Level } & \multirow{2}{*}{ St. Deviation } \\
\cline { 3 - 5 } & & No. & Percentage \% & Mean & \\
\hline Low & $0-1.33$ & 3 & 7.5 & & \\
Medium & $1.34-2.67$ & 28 & 70 & & \\
High & $2.68-4$ & 9 & 22.5 & 2.15 & 0.53 \\
\hline
\end{tabular}

Source; Survey results.

As shown in Table 3, the level of adopting extension recommendations by palm growers in study area was with an average of 2.15 indicating a medium level according to our classification in section 2.2 with a standard deviation of 0.53 .

5.4 Is There Any Impact of the Independent Characteristics (Variables) on the Degree of Adoption of Extension Recommendations?

The results of the statistical analysis for this question are shown in Table 4.

Table 4. Regression analysis on different variables associated with adoption

\begin{tabular}{lllllll}
\hline Variable & Mean & $\beta$ & $\mathrm{t}$ & $\mathrm{Sig}$ & $\mathrm{R}^{2}$ & $\mathrm{~F}$ \\
\hline Constant & & 2.359 & 2.588 & 0.018 & & \\
Education & & 0.195 & 1.822 & 0.043 & & \\
Age & 48 Years & 0.022 & 0.261 & 0.797 & 0.64 & 6.102 \\
Experience & 14 Years & 0.130 & 1.782 & 0.010 & & $(0.001)$ \\
Area & 47 Dun. & 0.112 & 2.183 & 0.036 & & \\
\hline
\end{tabular}

Source: Survey results.

As shown in Table 4, the $\mathrm{R}^{2}$ value was 0.64 indicating acceptable explanation of the variables effect. The table also shows that the variables; education level, experience, and farm area were with significant effect on the adoption of extension recommendations by farmers at a significant level of 0.05 . There was no effect of the farmer age on the adoption process. The table also shows that an increase by 0.195 degrees of extension recommendation adoption will be noticed with an increase of the education level by one level at 0.05 significance level. This is because the higher education level will result in much understanding of the recommendations by the farmers and the farmers will be more able to apply the extension recommendations in a proper way. The table reveals also that an increase by one year in the farmer experience will cause an increase by 0.139 degrees of extension recommendation adoption. This is an indication of the importance of the farmers experience in adopting extension recommendations. Concerning the farm area, the table reveals that an increase by one unit (dunum) in the farm area will cause an increase by 0.112 degrees of extension recommendation adoption. This means that larger area will be most beneficial in palm cultivation.

\section{Conclusions}

From the results of the present study we can conclude that there was a medium degree of adopting extension recommendations by palm growers in study area. Another conclusion is that recommendations related to the preparation and processing of the cultivation land, planting methods, and irrigation methods were the most adopted recommendations by palm growers in study area. The education level, growers' experience, and farm area variables were with significant effect on the adoption of extension recommendations by farmers.

\section{Recommendations}

Efforts should be made to increase the adoption of extension recommendations by palm growers. Realizing that preparation and processing of the cultivation land, planting methods, and irrigation methods were the most adopted recommendations by palm growers in study area it is recommended to concentrate on means for adopting other extension recommendations introduced by extension agents. 


\section{References}

Agbarevo, M. N. B. (2010). Effect of adoption of improved cassava production technologies by resource - poor farmers' on income from cassava in Cross - River State, Nigeria. Journal of Agric. Research and Dev, 4(3), $24-28$.

Agbarevo, M. N. B. (2011). Effect of adoption of improved cassava production technologies on input cost for cassava production among resource - poor farmers in Cross - River Stat, Nigeria. African Journal of Agric. Research and Dev., 4(3), 38-40.

Agbarevo, M. N., \& Obinne, C. P. O. (2009). An evaluation of the effect of agricultural extension delivery on cassava production in Nigeria: A case study of Cross- River State, Nigeria. The Niger. Agric. J., 39(1\&2), $16-21$.

Alawaideh, M. A., Fida, A., Najah, M., Samer, A., Moustafa, A., \& Aminh, A. (2008). The reality of palm cultivation in Jordan. agricultural credit corporation, amman, Jordan.

AlRimawi, A., \& Al-Habbab, M. (1996). Marketing and Agricultural Extension. University of Jerusalem, Open University.

AlSaab. (2008). The role of agricultural extension in educating farmers when the use of chemical pesticides. Processing cycle and the application of agricultural pesticides center in Riyadh.

Benjamin, A., \& Machiadikwe, N. (2013). The Effect of Adoption of Agricultural Extension Recommendations for Yam Production on Labour Among Resource-Poor Farmers In Cross- River State. Journal of Biology, Agriculture and Healthcare, 3(3).

Department of Statistics. (2012). Crops statistics. Jordan.

Hadrous, T. O. (2009). The measurement of Babel Governorate Growers adaptation of, the recommended Agricultural Extension. Euphrates journal of agricultural Sciences, 1(3).

Hamade, K. (2006). The Role of of Agricultural Extension to development palm cultivation in Alamara city. Journal of teacher university, 5(10).

Ministry of agricultural. (2013). Annual Report.

Ministry of Interior. (2012). Annual Report.

Opare, K. D. (1977). The role of agricultural extension in the adoption of innovations by cocoa growers in Ghana. Rural Sociology (EUA), 42(1), 72-82.

Sher, M., Chris, G., \& Kausar, A. (2001). Adoption of Recommended Agricultural Technologies by Farmers as an Indicator of Effective Communication by Extension Field Staff. International Journal of Agriculture \& Biology, 3(1).

\section{Copyrights}

Copyright for this article is retained by the author(s), with first publication rights granted to the journal.

This is an open-access article distributed under the terms and conditions of the Creative Commons Attribution license (http://creativecommons.org/licenses/by/3.0/). 